\title{
Political risk and the commercial sector - Aligning theory and practice
}

\section{Björn Fägersten}

Swedish Institute of International Affairs, Box 27035, 102 51, Stockholm, Sweden.

\begin{abstract}
The Arab Spring and the euro crisis have shown that political factors and events can make or break markets overnight, making them of increasing importance to commercial actors when investing abroad. Expropriation, sovereign default, societal unrest and terrorism are examples of political risks that have considerable implications for business conditions. They are also societal acts that political scientists have long been analyzing using a diverse toolbox of models, theories and methods. However, with a few exceptions, political risk management within commercial entities - in as far as it takes place at all - seems to rest on either anecdotal knowledge or crude quantitative macroeconomic data. This article tries to bridge the gap between risk management and the study of politics. It starts by analyzing the concepts and methods underpinning commercial risk management and continues with an investigation of contributions from relevant fields of political science. The aim is to contribute to the craft of risk management and the conceptual understanding of political risk.
\end{abstract}

Risk Management (2015) 17, 23-39. doi:10.1057/rm.2015.5

Keywords: political risk; business intelligence; risk management; new institutionalism; international relations theory

The online version of this article is available Open Access

\section{Introduction}

$\mathrm{P}$ olitical risk implies that a commercial or governmental entity's interests or objectives are potentially threatened by politically motivated action, in most cases on behalf of a foreign state. One might think therefore that the concept of political risk would be one of the defining themes of political analyses carried out by political scientists, but this is not the case. Instead, political risk is the latest add-on to the risk 
management approach that increasingly concurs with international business practice.

Risk management is an approach to strategy and decision making that is now widely applied in fields such as engineering, public health, environmental protection, finance and banking. At the core of the approach is a recognition that it is important to separate the likelihood of an event occurring from the consequences that will follow if it does (Bracken et al, 2008). Risk is the product of the likelihood and consequences, and risk management the process of manipulating the likelihood, the consequences or both in order to reach a more beneficial outcome, and constantly monitoring one's performance with these calculations in mind.

As globalization drives commercial interdependency and important markets can be found in volatile and unstable countries, commercial and governmental actors increasingly understand the importance of analyzing and managing the risks in their operating environments. Traditionally, such risk management has focused on economic risks caused by markets, customer preferences and commercial competition. The political environment in which business takes place was seen as a constraint, but a rather stable albeit unmanageable one. Its eventual impact was often - like that of the weather - confined to the statistical margin of error. Politics and economics were long regarded as separate realms, with only limited interaction between them. Today, however, most businesses recognize that political actions and decisions have major implications for commercial operations, and that they are easier to predict than the weather. For example, the nationalization of foreign direct investment (FDI) can have its roots in domestic politics, politically motivated terrorists are more likely to target some foreign companies than others and civil strife does not usually occur without signals and warnings.

However, when commercial actors set about analyzing the risks that originate from the political realm, more often than not they either employ patchy anecdotal knowledge and perceived 'common sense' or are astounded by the complexities of the political world (Bremmer, 2005). Little effort has been made to link this nascent art of political risk analysis to the methods and theories used by political scientists and academics in the field of International Relations (IR). This ignorance, however, seems to work both ways. While risk management has spread to a variety of issue areas, decision makers in the field of IR and national security have been slow to accommodate systematic thinking about risk (Bracken et al, 2008). Likewise - and perhaps as a consequence Jarvis and Griffiths argue that scholars of IR have been hesitant about utilizing risk management as a framework for analysis, preferring instead to hold on to their grand theories (Jarvis and Griffiths, 2007a, b). Thus, despite the popularity and sophistication of risk management and the increasing relevance of international politics to many commercial actors, three intellectual divides have been suggested: (1) Commercial actors increasingly use risk managements tools 
to analyze politics but make little use of theories and methods from political science, (2) scholars of IR seem to ignore the merits of risk management when studying and explaining IR, while (3) practitioners of IR seem to ignore the benefits of risk management as an approach to policy making.

This article addresses the first two divides and focuses on the possible interaction between risk management and political science. The aim is to shed light on this development, and to investigate the extent to which theories and methods of political science are relevant to the art of political risk management - and what the consequences might be if the suggested divides were ever bridged.

I start this overview by defining the three linked concepts under scrutiny political, risk and management - and showing how they are used in the risk management literature. I then briefly discuss how political risk management is conducted in the commercial sector before examining how theories of political science relate to the notion of risk management. I conclude with an analysis of how theories and methods can strengthen policy- and business-relevant risk management.

\section{Political Risk Management: A Conceptual Overview}

This section briefly discusses the three key concepts under scrutiny in this article. There is little consensus on the meaning of the specific concepts and even less so concerning the linked concept of political risk management.

\section{It's political}

The concept of political risk clearly originates in the political field but, beyond that truism, the views on what it means vary considerably. It is often negatively defined as 'non-market' risks. In practice this means that political risks are the factors that remain when analysts have considered economic fundamentals such as financial, currency, competitor and product risks as well as exogenous risks posed by, for example, extreme weather or natural hazards. This, however, still leaves considerable space for different interpretations. Usually, the interpretations of political risk vary with the interests of the specific actor as well as the context of analysis. In the heyday of neoliberalism and the 'small government paradigm' (the 1980s and the early 1990s), commercial analysts defined political risk as any government activity that impinged on the objectives of international business. Shapiro (1992), for example, defined political risk as a 'government intervention into the workings of the economy that affects, for good or ill, the value of the firm'. In line with the paradigm of the time, this implies that any orderly and legitimate activity of a government must be viewed as a potential risk. Three more or less independent developments have rendered this approach obsolete. First, and on a more general level, it is increasingly 
acknowledged that a certain amount of government intervention is benign for the business climate and increases commercial performance (North, 1990). Second, the increasing impact of non-governmental actors such as terrorists, local insurgents and international pirates, has widened the focus beyond just the activities of governments. Third, the 'failed states' that arose after the departure of the superpowers from peripheral areas at the end of the Cold War created more risk than 'big government' ever had. Recent scholarship usually defines political risks as encompassing more than government activity. Bremmer and Keat (2010) suggest that 'any political event that can (directly or indirectly) alter the value of an economic asset can be considered a political risk' and offer examples such as 'acts of terrorism, declarations of war and expropriation of private assets'. They do not, however, define what it is that makes an event political. Other scholars have turned to quality of government and state capacity variables, clearly departing from earlier perspectives. Here it is the lack of government, rather than the actions of governments, that constitute risk. Still others have stressed that a political risk must stem from political behavior and thus be actor-driven rather than an effect of dysfunctional institutions and systemic flaws (McKellar, 2010). In this article, I define political risk as a potential harm to commercial activities caused by political action or arising from dysfunctional political systems. The term 'political action' implies that a risk is only political if there are political interests behind it, leaving government intervention motivated, for example, by monetary policy considerations aside. Even if this working definition is not clear-cut, it leaves us with a somewhat more manageable concept of what constitutes the political in political risk.

\section{It's risky}

Compared to the meaning of political, the definition of the concept of risk is more or less universally accepted within the management literature. As noted above, risk is understood as the product of likelihood and consequence (Bracken et al, 2008) or probability and impact (McKellar, 2010) of a harmful event. These two measurements of risk are seen as independent of each other, although Brenner and Keat point out that analysts tend to think that catastrophic events (high impact) occur less often (low probability) than is statistically the case. More variance can be found in the literature on the issue of the object of risk. Commonly, political risk is seen as besetting multinational enterprises or businesses involved in FDI. This is unsurprising, given that political risk management in the commercial sector developed during the 1960s and 1970s when expropriations and the nationalization of foreign assets were common in the newly independent states of Africa and Latin America (Minor, 2003). Today, it is common to include both government agencies and non-profit actors that operate on foreign land as potentially subject to political 
risk (Bremmer and Keat, 2010). It is of course arguable that some forms of political risk, such as nepotism or civil strife, have equally harmful effects on domestic actors. Although this is certainly true, however, the motivations of the risk-creator, the nature of the risk and the means by which an exposed actor can manage risk vary considerably. Hence, political risk is usually seen as a concept pertinent to the asymmetrical relation between a business interest and a foreign state (Jarvis, 2004).

A last comment to make on the nature of risk is that it is more or less exogenous to the exposed commercial actor. In its most general form, a political risk is common to all actors operating in a specific environment, such as during a revolution or civil strife. Other forms of political risk are more closely tied to the specific operations of a certain actor, often because of controversial activities or the connection the public makes between a business and its origin. A good example is the boycott that hit the Scandinavian dairy producer, Arla, in several Middle Eastern countries during the Danish Cartoons crisis. It is also often the case that even though a company operates, and potentially misbehaves, on foreign land, the actual risk is at home - where vigilant regulators can react to corruption or breaches of established business conduct. Such domestic or even international reputational damage can be more severe than any local political risk, as for example Lundin Oil and Shell experienced in Sudan and Nigeria, respectively.

\section{But it can be managed}

Management is perhaps the most ambiguous of the three linked concepts. While all commercial risk managers agree that political risk can be managed - hence defending their raison d'être - it is far from clear from the literature what risk management actually means. Bracken, Bremmer and Gordon acknowledge that each field has its own frameworks, vocabulary and distinctions when engaging in risk management. The authors do not offer a clear definition of risk management, however, instead suggesting that it involves a 'conversation' about the likelihood and consequences that together constitute risk. They also add that risk management 'necessarily involves how risk is perceived, and how it's processed by individuals, groups, and organizations' (Bracken et al, 2008, p. 4). Mckellar, writing from a more practical viewpoint, argues that risk management is all too often seen as a reactive, trouble-shooting approach, when in reality it should be a strategic and foresighted process. Hence, he defines political risk management according to its function as 'enabling the fulfillment of objectives in even high-risk political environments' (McKellar, 2010, p. 115). When I discuss political risk management in this article I follow more general approaches to risk management, which view it as a process in which a concerned actor identifies, analyzes and in some way responds to a perceived risk (see for example Raftery, 1994). 


\section{Political Risk in Corporate Risk Management}

I now briefly turn to the practice of risk management, before contrasting this with the science of politics.

\section{Risk analysis}

A crucial part of any risk management process is identifying and analyzing the development of relevant risks. Darryl Jarvis argues that political risk analysis has gone through four more or less distinct phases (Jarvis and Griffiths, 2007a; Jarvis, 2008). The first generation of risk analysis focused on a set of political intrusions into what was assumed to be an efficient market. In other words, political risk was the effect of normal political activity. Risk analysis thus came down to a tick-box exercise against a list of common governmental practices that were thought to distort business profitability. This approach clearly simplified the role of both business and politics, and failed to understand their complex interaction. The second generation of risk analysis shifted its focus from specific governmental policies to the role of the political system at large and its vulnerability to stresses and shocks. The core assumption was that certain political systems are more prone to some types of risk than others. By characterizing states according to the system they belong to, analysts can know more about the sort of risks to which they are exposed. While this approach can generate interesting general insights into the risks associated with specific stages of political modernization, it provides little predictive power or assistance when planning operations in specific environments. Recognizing these shortcomings, third-generation risk analysts 'aim less towards grand theoretical correlations and more towards informed microanalyses that emphasize the importance of context, and focus on project-level analysis' (Jarvis and Griffiths, 2007a, p. 18). This has produced an increase in the use of qualitative techniques such as interviewing and scenario development, and a focus on methods rather than theory. Jarvis and Griffiths are, however, discomfited by this particularistic turn in the epistemology of risk analysis: 'The holy grail of political risk theorizing constructing quantitative models that can provide testable propositions, or the construction of data sets that can relate accurate probability indices to specific risk events, policy changes, or country settings - thus remains a highly prized goal, despite its difficulties' (Jarvis and Griffiths, 2007a, p. 18). The authors suggest that the way ahead - the fourth-generation risk analysis - 'involves the construction of data sets that allow analysts to examine the relationship between political and economic institutions, as well as the interface between domestic norms, actors, institutions and external influences' (Jarvis and Griffiths, 2007a, p. 18). ${ }^{1}$ Jarvis and Griffiths see promising work in this vein in the ambitious quantitative early warning systems that are being developed by NGOs, aid agencies and universities. These systems are hoped to be able to link 
institutional and contextual characteristics to the probability of risk events, and thereby warn decision makers of impending humanitarian crises and ethnic conflicts. As technological developments make such early warning systems available to a larger audience in real time, it is likely that a fifth generation of political risk analysis will be able to fuse complex qualitative models and scenarios with big data - for example from social media platforms. The way in which the 2014 Ebola outbreak was analyzed in real time, leading, for example, to adjustments in commercial supply routes, is indicative of the way the political risk industry is developing. ${ }^{2}$

\section{Levels of analysis}

Regardless of the method of analysis and level of theoretical sophistication, it is common among commercial risk analysts to distinguish between different levels of analysis. Although the terminology varies, the taxonomy usually implies a scale from a general birds-eye overview to a fine-grained outlook in which the commercial actor becomes increasingly endogenous to the analysis. McKellar, for example, distinguishes between global, country and operational levels of risk. At the global level, risks cut across all or many regions and affect all relevant actors. Country-level analysis focuses on risks in a given territory but still in the absence of specific operations. Operational-level risk analysis relates to the interaction between a specific business enterprise and its surrounding political environment (McKellar, 2010, pp. 72-73). Another common, but slightly more crude breakdown is between macro- and micro-level risks, where macro risks are non-project specific and affect all actors in a given setting while micro risks are project- and actor-specific (see for example Minor, 2003). It is not uncommon for macro risks to be habitually equated with global and/or country risks while micro risks are equated with local risk. This, however, seems to be analytically flawed as the geographical scope and the interaction of the specific risk taker and its environment are independent variables. Thus, for a full taxonomy of risk levels it would be possible to think of risks in a twodimensional metric that considers both the scope of the risk and the extent to which the risk taker has an effect on the development of risk. ${ }^{3}$

\section{Causes of risk}

Tied to the levels of analysis are the various causes of risk that actors face in different settings. Starting at the global and regional levels, Bremmer and Keat introduce geopolitical risks as the risks posed to economic actors and governments by the relative rise and decline of great powers and the impact of conventional wars on states and corporations' (Bremmer and Keat, 2010, p. 38). While this is exogenous to most commercial actors, other global risks, such as international terrorism, clearly pose a greater threat to some actors than others. At the country level, it can be useful to distinguish between risks caused 
by government action, such as sovereign credit defaults; risks caused by lack of government action or capacity, such as corruption of politically motivated crime; and risk caused by the fact that the government is being challenged, such as civil strife or insurgency. Much the same can be said of risks at the subnational level, with the difference that local governments, as well as its contenders, are more prone to intervene and obstruct specific business enterprises. At the local or project level, enterprises are also more likely to draw ethical criticisms - which some analysts term a political risk - simply because this is the level where their business activities take place.

Over time, the political risks encountered by commercial actors, as well as those encountered by governments, have moved from total losses owing to spectacular risk events to more complex and incremental risks. After the Second World War, the majority of political risks faced by companies had their roots in post-colonial nationalism and its effects. Essentially, blunt use of state sovereignty was the risk. In South America, Africa, the Middle East and South East Asia, Western companies and governments lost vast amounts of economic assets linked to the nationalization of private assets (Minor, 2003). By the early 1980s, however, times had changed. Developing countries, very much urged on by the International Monetary Fund and the World Bank, now saw the benefits of FDI and realized that expropriation of foreign capital rarely paid off in the long run (Bremmer and Keat, 2010; McKellar, 2010). Political risk during the 1980s was still a function of state control but had its roots in pressing economic developments. Perhaps the most severe risk was a sovereign debt default on foreign loans, most notably in Latin America (Minor, 2003). Although risk thus far to a large extent had been a function of the expression of sovereignty, it now shifted to be more a function of a lack of sovereignty. The inability of states to sufficiently monitor and regulate their financial markets was a major cause of the Asian financial crisis of the 1990s. The end of the Cold War and the withdrawal of great power support resulted in failed states that incurred risks for both citizens and outsiders. This was a precursor to the major geopolitical risks that dominated the first decade of the twenty-first century: international terrorism and its responses. Today, the global risk map is arguably even more complex, with risks originating from lack of sovereign control colocated with risks originating from the power of states. As examples of the failure of states to regulate and control, we see continuous offshore piracy in the Gulf of Aden, the spread of radical terrorist groups in the Levant and state failure in Yemen. Examples of the risks originating from the sovereign decisions of functioning states include a resurgent Russia threatening its neighbors, Greece contemplating leaving the eurozone and the United Kingdom contemplating leaving the EU. Interestingly, political risk - once a term used when investing in emerging markets with immature political foundations - is now just as relevant a concept in the Western, capitalist world. 


\section{What is at risk?}

What, then, is it that businesses and foreign governments stand to lose in the face of political risks? As noted above, some scholars state at the outset in their definition of political risk that it is the economic assets of companies or governments that are at risk. Other scholars argue for a broader view of the object of risk. McKellar, for example, argues that companies operating in politically volatile environments risk their people, reputation and performance. 'People' means that staff and their families are affected by risks. This is serious not only because staff members are key to business continuity, but also because a company's way of looking after its people is vital to its corporate culture. A company's reputation can be put at risk in its specific operating environment, at home and internationally. A reputation can be tarnished by misbehavior, for example, by choosing the wrong local partners or mismanaging community relations. Local political actors who orchestrate scandals or strife in order to vilify the firm can have a similar effect on a company's reputation. Finally, performance is simply the execution of business objectives, be it production, sales or R\&D. In the long run performance is largely dependent on people and reputation, but in the short term it can be seen as an independent asset at risk (McKellar, 2010, pp. 56-62). McKellar's typology offers the benefit of being equally relevant to governments' foreign businesses and commercial interests, and is thus utilized in the remainder of this article.

\section{Managing risk}

I have discussed above how risk is analyzed, its causes and its effects. This section discusses the final phase of the risk management cycle - what companies can actually do about and learn from risks.

Summarizing the above discussion, political risk can be understood as the probability and impact of a politically motivated action or system failure that negatively affects a given company's people, reputation of performance. Thus, managing these possibly adverse effects comes down to either making sure they do not occur or being better prepared in case they do. Most often a risk management strategy will involve both of these dimensions. The most extreme measures are directed toward the probability of risk: avoiding risk or trying to eliminate it. However, avoiding risk completely often equates to giving up a lucrative market to one's competitors, and is usually not an option. At the other end of the spectrum, eliminating risk is almost impossible. There is little a company can do about corruption, revolutions or terrorism - even states find this a challenging option, as the long hunt for Osama bin Laden illustrated (Bremmer and Keat, 2010, p. 192). Various strategies remain to improve one's position in the face of risk. At the strategic level, a company can adjust its risk exposure by balancing investments and operations in mature and more volatile markets. It is possible to spread risks by investing in several activities or 
adjacent countries rather than a single one. Note, however, that such a strategy actually increases the possibilities of risk while reducing the impact. Another approach, more attuned to the operational level, is to manage risk by taking physical security measures. Bodyguards, fences and bulletproof cars make it possible to deter some acts of political violence while at the same time reducing the impact of an attack. Security, however, is a double-edged sword. While possibly reducing risk to people and performance, tough security measures might increase the risk to reputation. Security is often contrasted to relationbuilding or societal engagement, although they are in no way mutually exclusive. By investing in infrastructure, public health and education, companies try to forge strong links with the local society. By doing so, companies hope to reduce the possibility of being victims of political schemes while also increasing their resilience in the face of them. Finally, there are various more technical hedging possibilities available for commercial actors. A company can form joint ventures with local, politically well-connected partners, they can forge alliances with powerful international actors to deter host governments from meddlesome intervention and they can invest in private or public risk insurance. In general, a successful risk management strategy must be holistic and address both probabilities and impact in the long and the short run. It is also worth pointing out that decreasing impact by way of improving resilience and relations will be useful in relation to unknown risks, while simply trying to reduce the probability of a specific risk has no positive externalities.

\section{Political Risk and Political Science}

Having covered political risk management from a commercial sector perspective, it is now time to turn to political science to see how it relates to the concept of political risk. As mentioned above, risk management scholars have addressed the various gaps between the risk management approach and the study and practice of IR. This article focuses on risk management in the study of IR and the extent to which there are possible synergies with the commercial sector's risk management approach.

\section{IR and the absence of risk}

To what extent do scholars of IR utilize and relate to the concept of political risk? According to Jarvis and Griffiths, not much:

Risk, or more particularly political risk, is thus a feature with a long history in International Relations (IR). Yet for such an endemic characteristic of the international system it has received scant attention in the academic discipline of IR.

(Jarvis and Griffiths, 2007a, p. 6) 
In another publication, the argument is slightly different:

Put simply. Risk analysis is the singular most important analytical tool of the modern world in large measure responsible for much of the economic, technological and social innovations we enjoy today. This makes it all the more strange that in International Relations (IR) risk has enjoyed much less attention; its utilization, theorization and application to understanding state-state relationships or state-market relations, for example, have remained mostly invisible.

(Jarvis and Griffiths, 2007b, p. 1)

Consequently, IR scholars - according to Jarvis and Griffiths - are blind both to the empirical presence of risk as something that ought to be studied and to risk analysis as a way of organizing and framing our scientific inquiries. Below, I challenge this view and discuss how risk exists particularly as an object of study but also as a tool of analysis within the study of IR.

\section{IR: Risky business}

Whatever terms are used, it seems clear that political risk is one of the main ingredients of IR scholarship. War and geopolitical discord, and the resulting effects on state-state relations are what have occupied IR scholars since the birth of the field. Power is no doubt the defining concept in realist accounts of IR. However, power is only relevant in its capacity to inflict risk on the system or inhabitants. Traditional realism made no distinction between the power of an actor and the level of risk it inferred to other actors in the system. Balancing power thus became a direct, although crude, risk management strategy. Focus, to use the terms of modern risk management, was not so much on the probability of discord as the consequences. Defensive realism, as manifested in the works of Stephen Walt, is more explicit in its use of risk as the key determinant of state behavior. By adding factors such as culture and geographical proximity, Walt increased attention on the probability of discord. His alliance theory is also an explicit risk management approach, where actors team up to spread risk among themselves and at the same time increase the risk for any possible aggressor. In this way, an aggressor may be deterred or defeated - a holistic risk management approach that addresses both the probability and the consequences of an attack (Walt, 1990). Two main points separate the realist perspective on risk from that of the corporate risk management approach. First, realists are predominantly interested in relations between states and pay little attention to non-governmental organizations and corporations. Second, realists have a rather narrow perspective on what is at risk - the survival of the state. To some extent, this would cover the risk management concept of performance, with less focus on people and reputation. 
The other major IR branch is equally tied to the concept of risk, but somewhat differently. In contrast to realists, liberals make utility, rather than power, their guiding concept. From a neoliberal perspective, however, utility can only be understood in relation to risk. Indeed, it is the risk management strategies of states - offering them opportunities to reap the gains of interaction - that constitute the main contribution of IR liberalism. Liberal scholars depend heavily on neoclassical economics when analyzing the utility of interactions such as gains in specialization and gains of scale. The problem for states interacting in an anarchic system is the lack of any supervising body ready to step in to enforce agreements, resolve disputes and establish property rights. Essentially, international interaction is plagued by risk. Liberal scholars, and perhaps most famously Robert Keohane, have shown how states, even in the absence of a hegemon or centralized enforcement, can produce mutually beneficial outcomes. They accomplish this by way of measures that decrease the risks of defection, manipulation and free riding. In Keohane's theory, regimes help states to cooperate by establishing patterns of legal liability, mitigating information asymmetries and making it costly for states to defect from cooperation (Keohane, 1984). Essentially, Keohane's regimes decreased the risk of cooperation by reducing uncertainty about the behavior and preferences of others. Liberal IR scholars lie closer to the commercial sector's risk approach than their realist colleagues. First, they accept that non-state actors are important actors in IR. Second, they have increased the interest in 'low-politics' and economic issues, the domain in which most commercial sector risks will be located. Third, they pay more attention to both people and reputation as referents of risk. Nonetheless, commercial risk analysts would probably argue that the grand theories of IR are too abstract, too general and too system-oriented to be of much use in analyzing political risk from a business perspective. However, much the same can be said about the second generation of commercial risk analysts described above.

Partly in response to the above failings of grand theorizing, mid-range approaches have grown in popularity in the IR field. These perspectives, such as new institutionalism and foreign policy analysis (FPA), are not as focused on risks pertaining to the international system, but nonetheless offer insights relevant to risk analysis. A good example is rational choice institutionalists who, like the IR liberals, were equally influenced by the field of 'new institutional economics' and the effects of uncertainty. However, unlike regime theorists who foresaw rather passive and decentralized cooperative arrangements, these scholars of institutions analyzed cooperative arrangements that functioned as more active providers of risk management functions. Institutional tasks could, for example, include monitoring compliance, identifying defectors and conducting research on developments in the cooperating states (Martin and Simmons, 1998; Koremenos et al, 2001; Hawkins et al, 2006). New institutional scholarship increasingly pays attention to the particular rather than the 
general, and has suggested ways in which specific institutions create risk, as well as opportunity, for the actors involved. Indeed, new institutional theory in large part responds to Jarvis and Griffiths' call for analysts to examine 'the relationship between political and economic institutions, as well as the interface between domestic norms, actors, institutions and external influences' (Jarvis and Griffiths, 2007a, p. 18). Another mid-range approach of relevance to risk analysis is FPA. Recognizing that system-level explanations have failed to capture the full variety of foreign policy choices, FPA scholars opened up the state box in order to broaden the analytical toolbox. Although the focus is on foreign policy output rather than risk management, FPA scholarship has been successful at synthesizing levels of analysis into coherent models. This is in stark contrast to the commercial sector's risk analysis, which often separates analysis into micro/macro or country/project. Another area where FPA scholarship is of specific relevance to commercial risk analysis is political motivations. As Brenner and Keat point out:

Unlike financial, economic, or environmental risks, political risks are usually generated by individuals, people with particular and identifiable sets of motivations and limitations.

(Bremmer and Keat, 2010, p. 21)

Although FPA scholars do not deal with risk per se, they have invested much time and effort in creating methodologies and theorizing about foreign policy decisions that create risk. A more rigorous and structured approach to mapping and analyzing the incentives and constraints facing local decision makers would undoubtedly benefit commercial risk management immensely.

Finally, while the study of IR is the main academic theme under scrutiny in this article, other areas of political science are of relevance to political risk analysis too. Thus far, I have mainly discussed the literature that focuses on the relation between the subject and object of risk; that is, the relations aspect of IR. Looking at political science in general, many of its subfields are of relevance for understanding the subject or object of risk, even when the relationship between them is not in focus. Starting with actors that find themselves - or their investments - at risk, the field of crisis management stands out as particularly relevant. Here researchers have pinpointed how actors make decisions under stress, how threats are perceived and communicated within organizations and what lessons can be learned in the aftermath of a crisis (Eriksson, 2002; Boin et al, 2006). Concerning the risk itself, or the environment from which it originates, other areas offer particular insights as well as more general findings. Different specialized fields offer insights on potential risks, be they terrorism, corruption, civil wars or monetary unions. Other researchers have produced more general scholarship on issues of great relevance to commercial risk analysis, for example on democratization and regime change (Teorell, 2010), 
the impact of different sorts of regimes on investments (Jensen, 2003; Jensen, 2008 ) or the relative quality of governing institutions (Holmberg and Rothstein, 2012), to name just a few.

\section{Aligning Art and Science}

The above survey showcases a rather clear pattern. While risk is not the organizing principle of most IR-theorizing, it plays an important role in several approaches to explaining IR. To argue that IR scholars have paid risk scant attention is thus only correct in a linguistic sense. It is true, although hardly surprising, that IR scholars have failed to adopt the terminology of commercial risk management. Nonetheless, as risk and risk management strategies can be found in several IR approaches, it is all the more surprising that commercial risk analysts have failed to take up the work of political scientists. To be fair, some commercial risk analysts have paid attention to work by political scientists in order to gather indicators and hypotheses on, for example, the reasons for civil wars, indicators of corruption and the causes of instability and state failure. ${ }^{4}$ Most of them have not, however, utilized political science as a way to organize and direct inquiry, as is discussed below. Perhaps the reason is one of epistemology. While political scientists often aim to identify general causes of specific outcomes, which in some cases allows for prediction, risk analysts are more interested in assigning probability to several outcomes. As probability levels in a specific case can hardly be falsified in the light of evidence, risk analysts have seen limited value in more traditional positivist political science. However, current ontological and epistemological shifts within political science increase its utility for the art of risk analysis. In laying out the core of modern institutionalist political science, Peter Hall argues that it has taken us away from assumptions about 'causal variables with strong, consistent, and independent effects across space and time toward ones that acknowledge more extensive endogeneity and the ubiquity of complex interaction effects' (Hall, 2003, p. 387). Political science along these lines will be more relevant to practitioners of risk analysis. More specifically, I argue that there are at least four areas, some of which were introduced above, where political science can be of direct relevance to commercial risk analysis.

First, political scientists have been rather successful at integrating and synthesizing levels of analysis as well as structure and agency into more or less coherent analytical frameworks. This is done within FPA, where individual leaders are connected to systemic variables by way of cognitive frameworks; it is done within new-institutional scholarship, where agents and institutions are seen as mutually constitutive; and it is done within IR theory, where interactions between domestic and international politics are studied as two-level games. The prospect of a political risk analysis that spans the commonly used 
levels of analysis (global, regional, country, project) and manages to endogenize the actors into the political environment in which they operate, is especially welcome, given the current state of the art of risk management.

Second, and also mentioned above, political science offers numerous ways in which motives, preferences and beliefs - and the way they affect political behavior - can be analyzed and theorized. As risk analysts acknowledge that the great majority of political risks affecting international enterprises are actordriven and intentional, a more robust way to study the incentives behind such actions would enrich the art of risk analysis.

Third, current political science, especially within the new-institutional field, is increasingly attuned to the interaction between local institutional characteristics and more general contextual and structural factors. This sensitivity to political particularity, while still aiming for 'bounded generalizations' about institutional effects, is especially welcome in cases where risk analysts monitor state failure and governance problems. It is exactly the risks tied to specific institutional solutions, in relation to more general exogenous shocks, that risk analysts need to be able to understand. The ambition to widen institutional research from traditional Western multilateral organizations to local and regional institutions will increase the benefit to risk analysis still further (Acharya and Johnston, 2007).

Fourth, risk analysts have much to gain from the focus on causal mechanisms that is now widespread within political science. Recognizing the limitations of proving causation by looking only at patterns of correlation, scholars from different fields have argued for the benefits of studying causal mechanisms as a way to infer causality (Elster, 1998; Tilly, 2001; Checkel, 2006). This implies that the researcher specifies - by way of deduction or induction - the way in which a cause produces an outcome. Rather than correlation, causality is thus inferred by the link between cause and effect. From the perspective of risk analysis, causal mechanisms could prove a powerful tool in assigning probabilities for specific developments as well as for crafting more robust scenarios. Risk analysis is often employed when there is plenty of information about the political environment but uncertainty about how a specific actor will be affected by this environment. In such contextually rich analysis, causal mechanisms prove their value, as it will be easier to assign probabilities to possible outcomes when each outcome is tied to the specific values of other variables and not only to their existence or nonexistence. The effect is that many outcomes that might have looked relevant from a correlation perspective become improbable when one considers the specific mechanism by which an outcome is thought to be produced. The utility of causal mechanisms is even more evident in scenario analysis, where well-specified mechanisms can be translated into robust indicators that can be used in turn to estimate which scenario seems to be unfolding.

In sum, there seems to be plenty that risk management gurus can learn from political scientists. Also, in a world where security parameters are increasingly 
uncertain, political scientists have much to gain from thinking more stringently about risk and risk management. John Quiggin has argued that risk is to the twenty-first century what globalization was to the twentieth (quoted in Jarvis, 2004). Compared to the concept of globalization, risk promises to be a more tangible lens through which to focus inquiry, and research based on risk has the potential to be of greater policy relevance. However, when engaging in risk analysis, IR scholars should be well aware, and make full use of the fact, that risk has been a key underlying concept in much IR theorizing to date.

\section{Notes}

1 Interestingly, short of the data set, the above sentence is close to identical to the battle cries of new-institutional scholars within political science proper.

2 For insights on the management of Ebola from a political risk perspective, see Cytora analysis (2014). On the integration of complex scenario building and real time data, see for example Bowman et al (2014).

3 Here it is important to note not only that company behavior or culture might affect the development of political risk but also that risk management practices might incur a risk for the host country. One example is when a country is publicly deemed unsuitable for investment, and another when rating agencies become active parties in the development they aim to analyze.

4 See for example the methodology behind the Eurasia Group's Stability Index

\section{References}

Acharya, A. and Johnston, A.I. (2007) Crafting Cooperation: Regional International Institutions in Comparative Perspective. Cambridge, UK; New York: Cambridge University Press.

Boin, A., t Hart, P., Stern, E. and Sundelius, B. (2006) The Politics of Crisis Management: Public Leadership under Pressure. Cambridge University Press.

Bowman, G. et al (2014) Stress Test Scenario: China-Japan Conflict. Cambridge Risk Framework series; Centre for Risk Studies, University of Cambridge.

Bracken, P.J., Bremmer, I. and Gordan, I. (eds.) (2008) Managing Strategic Surprise: Lessons from Risk Management and Risk Assessment. Cambridge, UK; New York: Cambridge University Press.

Bremmer, I. (2005) Managing risk in an unstable world. Harvard Business Review 83(6): 51-60.

Bremmer, I. and Keat, P. (2010) The Fat Tail: The Power of Political Knowledge for Strategic Investing. New York; Oxford: Oxford University Press.

Checkel, J.T. (2006) Tracing causal mechanisms. The International Studies Review 8(2): 362-370.

Cytora (2014) Analysis of Ebola as a political risk, available at http://blog.cytora.com/ analysis/ebola-geopolitical-risk/.

Elster, J. (1998) A plea for mechanisms. In: P. Hedström and R. Swedberg (eds.) Social Mechanisms: An Analytical Approach to Social Theory. Cambridge: Cambridge University Press, p. 45.

Eriksson, J. (2002) Threat Politics: New Perspectives on Security, Risk and Crisis Management. Ashgate. 
Hall, P.A. (2003) Aligning ontology and methodology in comparative research. In: J. Mahoney and D. Rueschemeyer (eds.) Comparative Historical Analysis in the Social Sciences. Cambridge, UK: Cambridge University Press.

Hawkins, D.G., Lake, D.A., Nielson, D.L. and Tierney, M.J. (eds.) (2006) Delegation and Agency in International Organizations. Cambridge University Press.

Holmberg, S. and Rothstein, B. (eds.) (2012) Good Government. The Relevance of Political Science. Cheltenham, UK: Edward Elgar.

Jarvis, D.S.L. (2004) International relations and international risk: Method and technique in political risk analysis. Paper presented at the International Studies Association, Montreal, Quebec, Canada, Le Centre Sheraton Hotel, Montreal, Quebec, Canada.

Jarvis, D.S.L. and Griffiths, M. (2007a) Learning to fly: The evolution of political risk analysis. Global Society 21(1): 5-21.

Jarvis, D.S.L. and Griffiths, M. (2007b) Risk and international relations: A new research agenda? Global Society 21(1): 1-4.

Jarvis, D.S.L. (2008) Conceptualizing, analysing and measuring political risk: The evolution of theory and method. Lee Kuan Yew School of Public Policy Research Paper No. LKYSPP08-004. Available at SSRN: http://ssrn.com/abstract=1162541.

Jensen, N. (2003) Democratic governance and multinational corporations: Political regimes and inflows of foreign direct investments. International Organization 57(3): 587-616.

Jenson, N. (2008) Political risk, democratic institutions, and foreign direct investment. The Journal of Politics 70(4): 1040-1052.

Keohane, R.O. (1984) After Hegemony: Cooperation and Discord in the World Political Economy. Princeton, NJ: Princeton Univ. Press.

Koremenos, B., Lipson, C. and Snidal, D. (eds.) (2001) The rational design of international institutions. International Organization 55(4): 761-799.

Martin, L. and Simmons, b.A. (1998) Theories and empirical studies of international institutions. International Organization 52(4): 729-757.

McKellar, R. (2010) A Short Guide to Political Risk. Farnham, UK; Burlington, VT: Gower.

Minor, J. (2003) Mapping the new political risk. Risk Management 50(3): 1.

North, D.C. (1990) Institutions, Institutional Change, and Economic Performance. Cambridge, UK: Cambridge University Press.

Raftery, J. (1994) Risk Analysis in Project Management. Taylor \& Francis.

Shapiro, A.C. (1992) Multinational Financial Management. Boston, MA: Allyn and Bacon.

Teorell, J. (2010) Determinants of Democratization: Explaining Regime Change in the World, 1972-2006. Cambridge: Cambridge University Press.

Tilly, C. (2001) Mechanisms in political processes. Annual Review of Political Science 4(1): 21-41.

Walt, S.M. (1990) The Origins of Alliances. New York: Cornell University Press.

This work is licensed under a Creative Commons Attribution 3.0 Unported License. The images or other third party material in this article are included in the article's Creative Commons license, unless indicated otherwise in the credit line; if the material is not included under the Creative Commons license, users will need to obtain permission from the license holder to reproduce the material. To view a copy of this license, visit http:// creativecommons.org/licenses/by/3.0/ 